\title{
A EPISTEMOLOGIA DAS POLÍTICAS PÚBLICAS EDUCACIONAIS E AS UTOPIAS DA SUA PRAXI NA EDUCAÇÃO NACIONAL
}

\section{ARTIGO ORIGINAL}

PEREIRA, Antônio Carlos Coqueiro ${ }^{1}$

PEREIRA, Antônio Carlos Coqueiro. A Epistemologia das Políticas Públicas Educacionais e as Utopias da Sua Praxi na Educação Nacional. Revista Científica Multidisciplinar Núcleo do Conhecimento. Ano 05, Ed. 10, Vol. 16, pp. 51-67. Outubro de 2020.

ISSN:

2448-0959,

Link de acesso: https://www.nucleodoconhecimento.com.br/educacao/a-epistemologia

\section{RESUMO}

A elaboração desse artigo tem como objetivo mostrar como as políticas públicas na educação brasileira tiveram um avanço primordial na garantia de uma educação de qualidade. Entretanto, tal avanço só ocorreu no papel, não sendo verificado em sua praxi no contexto nacional. Isto ocorre devido a velha política de interesses em não promover uma educação de qualidade. Sendo esta uma política retrógrada que não atende as Leis em relação a formação continuada dos professores da educação Básica para a promoção do saber e do compreender, visando inovar as práticas metodológicas educacionais afim de fortalecer a nação, impedindo que esta seja manipulada por quem ostenta o poder sócio econômico. Tem como linha de pesquisa qualitativa bibliográfica, com ênfase nos anais de teóricos que abordam tais conteúdos e temas. $O$ alvo desse artigo são os educadores e curiosos sobre as políticas públicas educacionais brasileiras e a sua história do passado que reflete no presente.

\footnotetext{
${ }^{1}$ Formação do Magistério do Segundo Grau; Graduado em Letras-Português/Inglês; Graduado e Pedagogia; Pós-graduado em Psicopedagogia; Pós-graduado em Gestão Escolar e Mestrando em Gerência e Administração de Políticas Culturais e Educacionais.
} 
Palavras Chaves: Políticas Públicas, praxi educacionais, formação continuada.

\section{INTRODUÇÃO}

A história da educação ao longo dos tempos, tanto na questão mundial, continental e nacional, vem sendo motivo de retaliação, de alienação e de enganação no que trata de favorecer os menos favorecidos e o que mais precisa dela, a educação. Temos como base na questão mundial, quando o surgimento na Europa antiga, medieval, moderna e contemporânea em que favoreciam a um gênero, neste caso, o masculino, a classe mais fortunadas, onde o clero, a classe nobre e quem tinha vínculos com famílias reais e nobres, depois veio a educação moderna onde continuava atendendo o interesse da burguesia e dos nobres, com acesso as Universidades e Liceus, adentro na Idade contemporânea onde a questão mais interessante era que falava em filosofia, sociologia, a busca da razão e da humanística e que só atendiam quem podia pagar ou ter um privilégio de ter o dinheiro.

Isso também não furta a educação do continente americano, em que para obter conhecimento e aprendizagem teriam que ir além do mar e estudar nos grandes centro europeus e quando esse indivíduo conseguia formar, voltava para a Nova Terra e iam ser tutor, pré-monitor ou até professor da elite, dos senhores de engenho, plantadores e criadores de café e de gado, mineradores ou parentes das nobrezas que tinha em cada país ou região do Continente Americano. A casta da educação que ainda podia contar com aqueles que tinham sorte e conseguiam ser agraciados com a boa ajudar de quem tinha condição. Depois a educação passou a ser classificada de acordo com a sua formação para homens e mulheres. A medicina, o Curso de Direito, os curso de engenharias e outras eram para a classe masculina e depois criaram as escolas normalistas, os liceus e as casas de câmaras onde as mulheres estudavam e tinham a formação em magistério (normal), culinária, administração dólar e de algumas profissões ligadas a arte do lar.

Ainda pode constatar que durante esses períodos, as unidades escolares eram em lugares onde atendiam as necessidades dos afortunados sociais e de cunho político. Nem todo lugar e nem toda a pessoa teve direito de ter uma escola perto de casa ou 
ter acesso a ela, a escola era motivo de sustentação de classe. A política escolar nacional, após a queda da monarquia, com o surgimento da republica, passou a pensar uma escola para todos, onde poderiam ingressar toda camada social, onde poderiam abranger mais a população de forma geral por todo o país e que facilitaria o acesso ao conhecimento e a aprendizagem para todos. Foi uma utopia sem nenhum pudor, pois o país tem uma dimensão em que dificultaria todos os lugares ter escolas, professores e condições para a sustentação dessas escolas nos cantos mais longínquos desse enorme país. A educação continuou sendo nos lugares mais desenvolvidos, melhores condições para atender aqueles mais favorecidos socialmente e infelizmente não conseguia atender toda a população. Ainda pode compreender o interesse dos políticos e dos dirigentes regionais em ter uma educação rudimentar e arcaico, onde podiam conseguir algumas pessoas que tinham um pouco de conhecimento para treinar e fazer copiar, as pessoas no interior do país para poder votar nos coronéis, o nome e fazer perpetuar a sustentação daqueles que tinham mais esperteza no poder.

Não é só de hoje que a educação é manipulada em nome de uma coisa que poderia ter acabado nos tempos anteriores e que hoje ainda continuam assolando aos menos favorecidos nesse pais que são as camadas mais pobres e o que sustenta a base da pirâmide etária são escadas de quem tem mais esperteza e condições de promover a alienação, a subjugação, o direcionamento, o encabrestamento de uma nação que dependia e depende da boa vontade de quem deveria promover a liberdade, a igualdade e o direito de todos ter uma aprendizagem ou conhecimento de um saber sistemático ou assistemático direcionado dentro de uma unidade de ensino. Ver uma máquina dentro de quatro paredes, que aliena, que humilha, que faz com que as injustiças sejam vistas em todo parâmetro do cotidiano de um sujeito que pensa em ser agraciado com um bondade, de órgãos governamentais, de órgão políticos sociais, de uma demanda para um todo, para ser uma pluralidade e não uma singularidade e por tudo ter uma conjuntura em que possa desenvolver não só uma minoria, mas sim um todo que tenha uma verdadeira e concreta política pública educacional. 
Sabe que as políticas públicas, no seu âmbito geral, deveriam ter um caráter popular, onde tem uma abrangência mais voltada para as camadas sociais desfavorecida e que o seu intuito é dar oportunidade para quem não tem. Isso seria uma dadiva de Deus se fosse assim no papel e na sua prática, mas infelizmente ver quem mais precisa as margens das políticas públicas e quem não precisa, está inserido até o pescoço sendo beneficiado, sendo favorecido e lutando para ter mais privilégios. Foi assim na época do Brasil Colônia, na época onde o Brasil foi uma Monarquia, na época do Brasil República, na época do Brasil dentro de uma ditadura vergonhosa e cruel, ver quando o Brasil passou por uma política selvagem de cunho neoliberalismo, ver isso dentro de doze anos de um governo socialista, onde teve uma melhora e hoje estamos dentro de uma recessão de uma política pública escancarada em que está na cara do fortalecimento da máquina administrativa e tendo corte onde não deve no seio social de um governo tendencioso a fortalecer o mercado estrangeiro e o imperialista.

Podem vivenciar isso claramente dentro da esfera educacional, onde fazem Leis inovadora, com intuito de promover ações educacionais que vão facilitar de forma coesa e concreta na educação da nação em seu todo, que reformulações são feitas a cada mandato de um governante, dizendo que vai melhorar as condição da educação do povo do país, onde a igualdade, a facilidade nas progressões escolares serão para todos sem distinção, falam que o plano de governo serve para diminuir a defasagem da idade série, facilitar o acesso dos jovens e da população nas universidades, independente de camada social, étnico-cultural e regional, onde diz que a educação é para todos e todas do país.

Mas o que é de verdade no papel, foge muito de ser uma realidade na sua pratica, pode enumerar várias ações ao longo do tempo que a pratica nunca chega a ser uma realidade, desde os tempos antigos da história até na contemporaneidade, as utopias do papel continuam utopia na sua pratica, sendo manobra de barganha, de favorecimento, de alienação e uma perpetuação do que se diz ser uma pratica real. Temos como exemplo o Manifestos dos Pioneiros da Educação no ano de 1932, liderado por Lourenço Filho e Anísio Teixeira, esse último teve o seu conhecimento e 
formação social nos Estados Unidos, onde a estrutura de educação tem uma diferença enorme e que queria implantar no Brasil, a educação continuou sendo de elite, utópica e com um leve cunho de hipocrisia. Desculpe a sinceridade.

Em 1961, em uma eminencia de um governo socialista, onde a vontade dos governantes liderados por Jânio Quadros e João Goulart, que queria diminuir o número de analfabetismo em zero em um período de quatro anos, para isso foi convocado o educador Paulo Freire e suas pedagogias para tal façanha, assim foi implantada a Lei número 4024/61 e que foram interrompidos quando o Brasil passou ter os "ANOS DOURADOS DO CHUMBO", quebrando toda vontade de ter um desenvolvimento educacional nos moldes dos país socialistas e populares.

\section{AS LEIS EDUCACIONAIS E AS SUAS DIRETRIZES}

Aí o retrocesso educacional veio a todo vapor com a Lei número 5.692/71, com reformulações de currículos, extinções de disciplinas no ensino fundamental II e no ensino médio, uma educação tecnicista e repetitiva em que não favoreciam ao aluno a pensar, analisar e ser crítico, uma tábua rasa. E na sua penúltima tentativa de fazer uma educação, que começou na Constituinte de 1988, onde começou apensar em uma educação libertária, critica, analítica e que seria um marco importante na educação brasileira, com valorização do aluno, dos professores e seus agentes educacional escolar, onde olhava para uma descentralização, ainda tímida, dos grandes centros e que trouxe muitas coisas importantes para evolução educacional do país, que foi a Lei número 9.394/96, que estabelece as Diretrizes e Base Nacional de Educação.

Foram implantadas algumas medidas que favoreceram de forma quase democrática a discutir o que era bom para o país, para a nação, para os alunos, para toda comunidade educacional que foram as realizações de conferências para entender o que é bom ou ruim para a educação nacional. Uma das primeiras Conferências foi a I CONEB, realizada em Brasília em 2008, onde foram homologadas as demais Conferencias a serem realizadas, a transformação de do FUNDEF em FUNDEB, onde foram implantadas as normativas para criação de Conselhos escolares e os recursos 
para o FNDE, a valorização dos recursos de acordo com a necessidade de cada região e demais programas que proporcionam o desenvolvimento da escola e do aluno no seio educacional e o mais importante foi a ratificação do Fórum Nacional De Educação.

O campo educativo, da escola básica à pós-graduação, no quadro do ajuste global, é, então, direcionado para uma concepção produtivista, cujo papel é o de desenvolver habilidades de conhecimento, de valores e atitudes e de gestão da qualidade, definidas no mercado de trabalho, cujo objetivo é formar, em cada indivíduo, um banco ou reserva de competências que the assegurem empregabilidade. (FRIGOTTO, 1998, p. 224).

De acordo com a citação acima, percebe-se que a educação ainda vive em um caráter de preparar as seus alunos em mais uma ferramenta de sustentação da mão de obra reprodutora de uma economia elitista e que não vai sair dos dogmas arcaicos em que sempre a escola e a educação foram atreladas para a sustentação de que estava ou está no poder de acordo com o momento em que passa o local onde o preceito está sendo empregado.

Hoje vive uma incerteza dentro da educação, quando não sabe o que poderá vir com essa nova Base Nacional Comum Curricular, onde no papel tem uma maravilha, buscando objetivos, práticas e habilidade tanto do aluno quanto do professor, o que mais preocupa é que quando se trata de algo que é do notório saber do professor, onde tem a segurança de orientar aquilo que sabe, entende e sente segurança no que poderá fazer para fortalecer essa Base Comum, vem a preocupação e o questionamento, será que o professor está preparado para colocar em pratica o que propõe esses novos parâmetros? Aí volta a lembrar da velha premissa onde a educação nos tempos de hoje, vai e voltar para aquele caráter elitista, onde a preparação dos novos orientadores ou professores não está sendo condizente com o que diz a bendita lei. Será que o MEC, a CAPES, o INEP sabem que a quantidade de professores a nível municipal, estadual da educação básica, quase na sua totalidade não tem uma formação continuada para adequar o que diz a BNCC? Será que não vai ser mais uma utopia ou hipocrisia o que os governos querem impor na clientela educacional e para a nação brasileira? Fica esse questionamento. 
Neste ponto é que pode preocupar com a política pública que está dentro da Lei número 9.394/96 EM SEU Artigo 62, parágrafo III, que trata da formação continuada do professor para poder ter as novas formas de conhecimento para usar em novas metodologias em fazer com o aluno aprenda dentro desse novo Parâmetro Curricular. Vejam os empecilhos que encontra o educador da Educação Básica.

\section{A ESCOLA E A FORMAÇÃO CONTINUADA DOS PROFESSORES PARA UMA METODOLOGIA INOVADORA}

Um tema que está sempre em evidência na área educacional é a formação continuada dos agentes educacionais para a prática pedagógica dentro de uma unidade escolar. Sabe que a escola vem sofrendo modificações dentro das suas propostas educacionais, como dentro do sistema escolar e quando fala em uma educação fora dela. Hoje coloca muito o chamado sistema educação domiciliar, pode observar que o órgão que gerencia a educação pública do país quer de uma vez por todas fazer com que qualquer um possa ter o faculto de lecionar e de ensinar fora do sistema educacional escolar.

Sabem que existe uma Lei que faz com que o educador que está na ativa tenha uma graduação com licenciatura ou bacharelado que tenha uma complementação para exercer o direito da docência, outras unidades educacionais vem maquiando o sistema educacional com o emprego dentro das faculdades ou mesmo de universidades o emprego do tutor como viés para suprir a função do professor. A palavra "tutor", segundo o dicionário Aurélio, diz que a palavra tutor significa aquele que guarda, aquele que recebe a função de guardar e poder de tutela de algo, mas nunca refere como professor que emprega a arte do magister. Percebe que a sonhada formação continuada daqueles que estão na ativa, pode perder o espaço para as novas diretrizes que vão dificultar cada vez mais o aprendizado de qualidade e de poder ver um pais que depende do conhecimento escolar e de formação de muitos seres pensantes, de proporcionar uma qualidade de desenvolvimento tecnológico e de qualificação para a ampliação de uma área tecnológica, voltar para o ensino 
rudimentar e sem uma condição para competir com os países que estão na vanguarda da educação.

Outra situação que ainda permeia nos departamento da CAPES, órgão vinculado ao Ministério da Educação e Cultura do Brasil, limitam vagas para os professores galgarem um curso de qualidade dentro das universidades públicas gratuitas, sendo muitas vezes por pessoas que não estão em sala de aula, pessoas que tem um estimulo ou coparticipação de projetos e conseguem vagas sem estarem na ativa do ensino público dos sistemas educacionais brasileiros que são a rede municipal, estadual e federal. A formação continuada abre leques tanto para professores que estão a muito tempo na sala de aula quanto para os novatos que precisam sempre estar atualizando métodos para a sua prática profissional. A formação continuada dentro da escola pública para os seus educadores, poderia ser com mais facilidade, com maior número de vagas e sem clientela apadrinhado. Principalmente profissionais de escolas de área de riscos, de difícil acesso para os grandes centros e escolas quilombolas, do campo e o EJA.

É preciso trabalhar no sentido da diversificação dos modelos e das práticas de formação, instituindo novas relações dos professores com o saber pedagógico e científico. A formação passa pela experimentação, pela inovação, pelo ensaio de novos modos de trabalho pedagógico. $E$ por uma reflexão crítica sobre a sua utilização. A formação passa por processos de investigação, diretamente articulados com as práticas educativas. (NÓVOA, 1995, p.28)

Segundo Nóvoa (1995), faz necessário trabalhar a diversidade das práticas metodológicas para obter novas relações com o conhecimento pedagógico, o cientifico e com o conhecimento vivência inata para o que pode ser adquirido ou empregado dentro das academias de formação para a prática do magister. Muitas vezes pode considerar que o conhecimento possibilita que o educador pesquisador $\mathrm{e}$ leitor tenha mais facilidade de "brincar" dentro da forma ensinar, ter uma variedade de emprego metodológico para cada tipo de turma, alunos e de escolas.

A educação deve ser libertadora, sem dogma ou paradigma, sem atrelar os conhecimentos de teóricos ou de uma tendência que fica arraigada ao velho sem 
tentar buscar o novo, assim pode dizer que a educação precisa inovar, transformar seus agentes e adquirir um conhecimento ou uma formação continuada que possibilite o educador voar sem ter asas no que se trata de relacionar o seu novo conhecimento com uma pedagogia ou método fascinante e que possa motivar perpetuamente a sua clientela.

É necessário enriquecer a aprendizagem com as ciências mais estimulantes do século XXI. A pedagogia e o trabalho do professor estão ainda muito fechados nas psicologias do desenvolvimento, nas psicologias de Piaget, em certas sociologias do século XX. A pedagogia precisa respirar. Os professores precisam se apropriar de um conjunto de novas áreas científicas que são muito mais estimulantes das que serviram de base e fundamento para a pedagogia moderna. Como, por exemplo, todas as descobertas das neurociências, sobre o funcionamento do cérebro, as questões dos sentimentos e da aprendizagem, sobre a maneira de produzir a memória, sobre as questões da consciência. Trata-se de um conjunto de temas que temos integrado mal à pedagogia. Falo da psicologia cognitiva, das teorias da complexidade - que dizem, contrariamente às nossas convicções, que nem sempre se aprende de maneira linear, nem sempre se aprende do mais simples para o mais difícil, do mais concreto para o mais abstrato, que aprendizagem é de uma enorme complexidade. A profissão docente está ainda muito prisioneira da pedagogia moderna, fundamentada nas ciências psicológicas e sociológicas do século $X X$, não consegue se enriquecer com os contributos, que são, no século XXI, os mais interessantes das ciências contemporâneas. (NÓVOA, 2007, p. 07).

Segundo o autor da citação acima, a pedagogia está sendo sufocada pela ciência psicológica do desenvolvimento, da estruturação de como aprender a teoria de Piaget e não enfocar a necessidade do educador, focar em outras ciências que façam com que o educando saia do cotidiano educacional e que façam ser compreendida a necessidade de novos conhecimentos junto a unidade escolar, uma aprendizagem que busque o real do irreal, da pratica junto com a teoria, da formalidade sobre a informalidade e assim o educando buscará um prazer no que vai e no que quer aprender. $\mathrm{O}$ educador tem que desprender muitas fórmulas prontas, pesquisar e ler para desenvolver novos conhecimentos e para elaborar novas metodologias. 


\section{O FAZ DE CONTA DA FORMAÇÃO CONTINUADA PROCESSO NO CENTRO ACADÊMICO}

Quando fala que a educação pode ser transformadora na vida de uma pessoa, que tira de um estado de inercia, tornando um ser participativo, crítico e libertário dentro de uma sociedade em que a cada momento faz com que esse cidadão tenha necessidade do conhecimento, regras sociais, de uma capacidade de expandir desenvolvimento para ele e os demais membros dessa sociedade possam ter conforto, liberdade e a necessidade de serem independentes. Hoje ver uma escola despreparada, professores com necessidade de ter uma formação continuada, não só para o seu emprego metodológico, mas para obtenção de conhecimento para poder diversificar a sua metodologia em situações necessárias dentro da sala de aula de acordo com a necessidade de cada aluno ou dos alunos em geral.

Assim, pode dizer que o desempenho de cada profissional, da escola dentro de uma sociedade, faz necessária a formação de cada professor orientador, de uma formação que tenha tato no que tange a preparação do Plano Político Pedagógico, o comprometimento da sociedade para com a escola e principalmente a participação dos pais dos alunos na formação do referido documento. A escola que tem uma parceria social, que busca ser democrática e igualitária sem distinguir clientela, sem ter uma conjuntura para só preparar seus alunos para a vida profissional em que vão continuar sendo vítimas de um processo que na maioria dos países, governos e sistemas, quer alunos com capacidade de ter uma expansão intelectual em ser um mero tijolo de um muro que vai aprisionar para a sua vida toda. A escola é o caminho transformador quando ela é bem gerida, quando é bem ligada a comunidade e quando faz com que os seus alunos pulem o muro da prisão educacional para buscar a sua liberdade, a sua forma de ser agente de transformação social. As escolas atuais, na maioria da vezes, não emprega o que a pratica teórica que se aprende nas academias e que são cobradas nas atividades acadêmicas em que os professores são obrigados a empregar na sua prática de aprendizagem acadêmica, dentro de uma realidade pratica e necessária dentro do universo chamado escola. 
Quando se diz os saberes que ostenta os pilares da educação, muitas vezes leem e não enxergam o que realmente quer dizer na sua prática, sente uma emoção quando lê e não sente a obrigação de empregar dentro da realidade escolar. Do que adianta conhecer, estudar, colocar em prática dentro das academias e não colocar em prática na realidade depois de ser formado, preparado para sentir na realidade desses saberes para um educando. Vejam o que diz esses saberes: Aprender a Ser, Aprender a aprender, Aprender a conhecer, Aprender a conviver, Aprender a valorizar, Aprender a preservar, Aprender a recomeçar e Aprender a transformar (DELORS, 2012), A Universidades e Faculdades faz com que professores entendam esse legado para a educação e quando saem dessas instituições parece que esquecem e voltam a praticar atos que lembram a velha educação, a forma tradicional de fazer com que os alunos tornem "tijolos" para sustentar elites e serem explorados.

A escola com um programa voltado para seguir um plano político pedagógico libertário precisa que os seus orientadores professores sejam praticantes de formações continuada para melhor praticar, através dos seus conhecimentos, metodologias inovadoras. A escola do século XXI, na sua minoria pratica uma forma em que emprega a principal necessidade de habilidades que os alunos necessitam para desempenhar a sua cidadania perfeita, além de ter uma capacidade de sobressair ao meio de muitos fatores que faz com que ele, o aluno cidadão, em relação dos que são mais afortunados em seu emprego economicamente. A escola libertária para o século XXI necessita de professores orientadores libertários, professores orientadores democráticos, professores sociáveis e que façam com que os seus orientados possam ser capazes de competir com igualdade na sociedade. Viver a educação precisa de esforço motivacional, precisa de comprometimento, precisa de resiliência e acima de tudo uma boa metodologia. Outro ponto marcante dentro da educação e que podam a unidade escolar ser igualitária é a de que existe uma jogatina impiedosa de cadastrar essas unidades pedagógicas para o órgão superior nacional educacional de acordo com a modalidade de cada instituição de ensino. Por ser escola rural, ser cadastrada como escola do campo, sabendo que essa escola do campo é amparada por leis diferentes, por emprego funcional administrativo e metodológico diferente. 
A questão que a escola está inserida dentro de uma esfera econômica é humilhante e vergonhosa, temos como exemplo a questão da vinculação do repasse da União para os municípios de acordo com o número de alunos, a vinculação de recursos por escola, vinculada ao número de alunos e pôr tudo a questão dos vencimentos do profissional da educação também vinculado ao número de alunos que deveriam ser vinculados por necessidade, por desempenho e por tudo por questão de necessidade geográfica espacial. Regiões mais pobres ou escolas que estão inseridas em áreas de risco social, em que a comunidade, os integrantes que estão dentro desses fatores requerem mais incentivo financeiro, de competência e habilidade de metodologias e de conhecimento para desenvolver o seu papel social como agentes transformadores de práticas sociais.

[...] ensino por competências é representado pelos planejamentos para os quais a funcionalidade é a meta de toda a educação, de modo que o aprendido possa ser usado como recurso ou capacitação adquirida no desempenho de qualquer ação humana, não apenas nas de caráter anual, as também nas de consulta (exercer comportamentos), intelectuais (utilizar uma teoria para interpretar um acontecimento ou fenômeno), expressivas ou de comunicação (emitir mensagens) de relação com os outros (dialogar). Pedir competência nesses casos é, simplesmente, cobrar efetividade do que se pretende na educação (SACRISTÁN, 1995).

Segundo Sacristan (1995), a educação e os seus agentes necessitam sempre serem promovidos através de conhecimentos e que esses conhecimentos possam desenvolver tais habilidades e competências aos educadores agentes de transformações como o incentivo na sua formação, na valorização do seu trabalho, sendo financeiro ou de promoção de classe ou de uma forma que motive quem está sendo o interlocutor ou mensageiro do conhecimento, ou quem está recebendo o conhecimento que o aluno no seu estágio final que é a escola.

Ante os múltiplos desafios do futuro, a educação surge como um trunfo indispensável à humanidade na sua construção dos ideais da paz, da liberdade e da justiça social. Ao terminar os seus trabalhos a Comissão faz, pois, questão de afirmar a sua fé no papel essencial da educação no desenvolvimento contínuo, tanto das pessoas como das sociedades. Não como um "remédio milagroso", não como um "abre-te sésamo" de um mundo que atingiu a realização de todos os seus ideais mas, entre 
outros caminhos e para além deles, como uma via que conduza a um desenvolvimento humano mais harmonioso, mais autêntico, de modo a fazer recuar a pobreza, a exclusão social, as incompreensões, as opressões, as guerras...(DELORS, 2003, p. 11)

De acordo com a citação em uma análise, para conseguir tal desenvolvimento, cabe aos órgãos que fazem parte do processo educacional, que possibilitem seus agentes transformadores capazes de serem transformadores e para isso cabe uma educação e formação continuada concreta, que não fica só nos projetos e que sim, tenha uma eficiência plural nas unidades federativas do país e dentre os municípios que compõem todos os estados da federação.

$\mathrm{Na}$ perspectiva de um sistema de educação que ainda possui metodologias constituídas por preconceitos implementados na época do ensino tradicional , onde ato de aprender se baseia em conhecimentos bancários, e o saber se caracteriza na limitação de aprender conteúdos que satisfazem um sistema de educação vinculado a quatro paredes, sem qualquer contextualização de um conhecimento precedente para o conhecimento sistemático tradicional; uma educação que tem como primazia a ostentação de status, numa cadeia divisória daquele que ensina, coordena e gerencia, tratando como menos importância o processo ensino aprendizagem, os alunos.

Numa educação em que há a importância do emprego de metodologias e conteúdo para a questão profissional de quem está aprendendo sem se preocupar com o pensamento racional, social, coletivo e crítico daquele que precisa se tornar um ser crítico, participativo, capaz de transformar dogmas e estigmas ao longo do seu desenvolvimento pessoal, como um ser vivo e social.

A educação sempre apresenta uma ideologia falaz em conformidade com o que é proposto pelos governantes e dirigentes educacionais quanto ao desenvolvimento da educação moderna, progressiva e transformadora. É uma dissimulação enganadora e não prática, onde as escolas são alienadas a uma gama de conteúdos que muitas vezes são transmitidos de forma incompleta e errônea, sem uma pluralidade de mecanismo em âmbito regional, estadual e nacional, imperando o que podemos chamar de uma educação elitista e singular. 


\section{A FORMAÇÃO CONTINUADA COMO ATO DE CONHECIMENTO, DE FORMULAR NOVAS METODOLOGIAS E DE COMPREENSÃO DE MUNDO PARA O EDUCADOR}

Questionar sobre a capacidade de pensar de um indivíduo que tem uma formação cultural voltada para aquilo que tudo que vê e compreende, o que está vendo e sente e a necessidade de comunicar o que está perceptível com o outro. Foi assim que começou, o ser humano a falar. Pode também tomar como base, a evolução do homem erectus para o homem sapiens. Com a transformação da cabeça na forma atual e do alongamento do pescoço. No decorrer desse desenvolvimento, o homem não parou de falar e transmitir culturalmente o que pensa, o que sente, o que incomoda, o que o aflige, o que entende do que é correto e do que é errado.

Essa habilidade foi capaz de formular o surgimento de várias ciências que estudam a questão da fala, como o homem fala, como é a forma da falar, os idiomas no mundo falante com suas origens, gramática linguística. Assim surgiu a sociolinguística. Muitos desses teóricos vieram fazer com que o universo social da língua fosse estudado historicamente de acordo com as conquistas através das guerras do poder de sustentação de culturas e economia, fez aparecer as novas multiculturas da linguagem como idioma e como costumes de vivência e de sobrevivência mundial.

O mecanismo que faz o ser humano pensante a transmitir em forma de voz é o ar e o deslocamento da epiglote que é capaz de fazer com que o ar emita o som que nos possibilita a nos comunicarmos com a fala. A ramificação linguística pelo mundo é de uma tamanha proporção que não tem como saber a quantidade de idiomas (línguas) falados. Calculam que existem mais de três mil idiomas no mundo e que até o momento não tem uma certeza de qual é o idioma "mãe". Alguns estudiosos, em algumas publicações comentam que pode haver uma igualdade de tempo para definir qual foi o primeiro idioma falado, pois tendem a dizer que podem surgir vários idiomas ao mesmo tempo em lugares diferentes e outro já põe em dúvida essa teoria porque existem várias palavras em idiomas diferentes que coincidente ou não, assemelham. É o caso do pronto indo-europeu, o sânscrito e o indo-europeu. 
A fala que veio ao mundo através da evolução do crânio e das partes que fazem o aparelho fonador a emitir a voz, foi capaz de criar ao homem o poder mais certificante que possa existir na compreensão humana que foi a fala. Com a fala e seus conjuntos de palavras, tornou o homem a obter o maior instrumento que tem para mobilizar várias mentes, ideologias e ceticismo. Esse instrumento foi empregado ao longo da história da humanidade, nos quatro cantos do mundo. Uma ferramenta de manipulação, subjugação e até mesmo de punição que foi o discurso. Esse discurso levou ao homem com o poder da oratória a ser um sujeito capaz de dominar várias camadas da sociedade em diversos lugares, culturas e de uma poderosa economia. Podemos enumerar vários personagens que usaram a oratória para manipular massas, reinados, parlamentos, refutar e oprimir culturas e religiões e separar o mundo por ideologias econômicas, racistas e de sofrimento.

A Análise de Discurso não estaciona na interpretação, trabalha seus limites, seus mecanismos, como parte dos processos de significação. Também não procura um sentido verdadeiro através de uma chave de interpretação. Não há esta chave, há método, há construção de um dispositivo teórico. Não há verdade atrás do texto. Há gestos de interpretação que o constituem e que o analista, com seu dispositivo deve ser capaz de compreender. (ORLANDI, 2009, p. 26).

Pode perceber na história religiosa da origem do homem, do pecado carnal que Deus colocou ao homem, na história da morte e ressureição de Cristo, na idade medieval, na idade moderna e na contemporaneidade. O discurso, na capacidade de um homem faz com que torne uma arma poderosa que transforme um plebeu a um Lord ou até em um premier. O homem no seu ato de comunicar, adotou certas regras para emoldar a fala, o discurso e a oratória que foram as regras de linguagem ou a gramática. Assim pode conciliar a fala com a escrita. Neste contexto, a escritas foram criadas pelos Sumérios, através dos hieróglifos, dando o signo para cada letra falada e assim foram criadas as palavras.

O discurso foi tão significativo na modernidade, que muitos teóricos e filósofos tentaram mostrar como pode ser muito poderoso o que é falado, sendo transformado como armas de manipulação ideológica e chega até ser motivo de estudo através da análise do discurso. Todo discurso pode ser transformar em uma forma de poder, 
gerando conflitos que permeiam a uma verdade ou uma inverdade, vai depender do potencial de quem está pronunciando esse discurso. Pode perceber que o discurso em si, pode ser objeto de manipulação de tudo ou de todos sobre um interesse individual ou coletivo.

Assim pode observar na obra de Michel Foucault, Pierre Bourdieu, Mikail Baktin e Saussure. São estudiosos no que trata ao discurso, a compreensão da comunicação sobre o que está sendo falado e sua mensagem para quem ouve.

[...] todo discurso esconde uma rede simbólica de relações de dominação ideológica e de poder. Cada palavra expressa no ambiente organizacional está, de alguma forma, sendo monitorada e classificada. Todo discurso que destoa da sinfonia organizacional é reprimido, não necessariamente através de punições coercitivas explicitas aplicada pela direção central da organização, mas através dos grupos internos, do controle psíquico da ideologia. Há uma delimitação imaginária [...], em que o indivíduo pode se aventurar com o uso de suas palavras, diálogos e argumentações, devendo estar, contudo, atento para que o seu discurso não ponha em risco os grupos dominantes e a ideologia vigente na organização (FARIA e MENEGHETTI, 2001, p. 1).

Segundo Faria e Meneghetti (2011), todo discurso tem o poder de "doutrinar" aqueles que são vulneráveis a percepção do enunciado e dependendo da situação, até fragilizado com situações que se encontram adversas, diz ainda os autores da citação, que o discurso pode ser premeditado de acordo com o interesse ideológico de quem quer chegar ao objetivo de poder conseguir controlar e mudar o sentido ideológico de uma grande massa. O discurso central pode ser indireto, através de um enunciado preliminar para chegar ao tema central que o verdadeiro motivo onde o orador que determina sua oratória dominadora.

Muitos desse oradores estudam o lado mais vulnerável, por motivo de falta de conhecimento do que está acontecendo, por uma esperança acabado ou por uma frustração de um poder que não está dando certo. O discurso é uma ferramenta para doutrinar e perpetuar um pensamento que tende ser algo salvador. Pode relacionar a análise do discurso com uma gama de conhecimento, esse conhecimento pode refutar alguma ideologia proposta no discurso devido ao conhecimento de quem ouve, ter um poder de concentração e de percepção do que o discurso está anunciando. 
[...] em relação a hoje e à nossa própria condição, creio que estamos diante de uma situação nova na história, porque temos que ser libertados de uma sociedade rica, poderosa e que funciona relativamente bem. $\mathrm{O}$ problema que enfrentamos é a necessidade de nos libertar de uma sociedade que desenvolve em grande medida as necessidades materiais e culturais do homem - uma sociedade que, para usar um slogan, cumpre o que prometeu a uma parte crescente da população. E isso implica que enfrentamos a libertação de uma sociedade na qual a libertação aparentemente não conta com uma base de massas. (MARCUSE, 1973, p. 277).

Assim, pode dizer que um povo que tem um poder do conhecimento não será manipulado com qualquer discurso, mesmo sendo o orador hábil na arte de pregar um discurso convincente. Pode perceber que não há discurso sem o sujeito e nem o sujeito sem uma ideologia. Assim percebe que o discurso está irmanado com a ideologia e que a ideologia está de forma conceituada no sujeito. O sujeito ideológico pode estar cabível a doutrinação ideológica e pode ser um agente de manipulação ideológica através do seu discurso.

\section{CONCLUSÃO}

Portanto, falar das políticas públicas educacionais brasileiras, no seu contexto geral, fica uma incógnita que não tem uma resposta concreta, sabe que tem uma Lei forte e firme no papel, que tem até um sentido positivo se colocasse na pratica nas esferas dos entes federados e não ver essa pratica ser colocada à prova. Quando se fala em uma base comum, entende que deve existir uma igualdade educacional na sua pratica a nível nacional e como deve chegar a essa igualdade? Como pode ter uma educação de qualidade sem não tem um investimento real, não aquele que só configura na lei e no papel da formação continuada dos professores da educação básica? Sabe que temos uma diversidade cultural enorme, um espaço geográfico enorme e desigual em todos os âmbitos em que diz no contexto cultural, econômico, territorial e sem contar que ao longo dos anos até a proporcionalidade de investimentos e desenvolvimento das regiões eram desproporcional. Então não pode colocar e esperar um resultado positivo no que trata a uma base comum curricular para obter uma educação de qualidade a nível geral. 


\section{REFERÊNCIAS}

BOURDIEU, P. Sociologia. São Paulo: Ática, 1983.

. Contrarrevolução e revolta. Tradução de Álvaro Cabral. Rio de Janeiro: Zahar, 1973

DELORS, J. Educação: um tesouro a descobrir. 2ed. São Paulo: Cortez Elabore três tipos de fichas (citação, resumo e analítica) com base no texto: "Os 4 pilares da Educação" de Jacques Delors. Brasília, DF: MEC/UNESCO, 2003.

. Desenvolvimento profissional de professores para a qualidade e para a equidade da Aprendizagem ao longo da Vida. Lisboa: Universidade de Lisboa, set 2007a, disponível no site: www.eu2007.min-edu.pt

FARIA, J. H.; MENEGHETTI, F. Ética e genética: uma reflexão sobre a práxis organizacional. Anais do XXV ENANPAD, Campinas, 2001b.

FARIA, J. H.; MENEGHETTI, F. O sequestro da subjetividade. In: FARIA, José Henrique de (Org.). Análise crítica das teorias e práticas organizacionais. São Paulo: Atlas, 2007. p. 45-67.

FARIA, J. H.; MENEGHETTI, F. O sequestro da subjetividade e as novas formas de controle psicológico no trabalho: uma abordagem crítica ao modelo toyotista de produção. Anais do XXV ENANPAD, Campinas, 2001a.

FRIGOTTO, G.; FAVERO, O.; HORTA, J. Políticas educacionais no Brasil: desafios e propostas. Caderno de Pesquisa, n.83, p.5-14, nov. 1992.

MARCUSE, H. Ideias sobre uma teoria crítica da sociedade. Trad. Fausto Guimarães. Rio de Janeiro: Zahar Editores, 1981.

MARCUSE, H. Ideias sobre uma teoria crítica da sociedade. Tradução de Fausto Guimarães. Rio de Janeiro: Zahar, 1972. 
NÓVOA, A. Desafios do trabalho do professor no mundo contemporâneo. São Paulo: SINPRO, 2007. Texto da Palestra proferida em outubro de 2006, disponível no site: www.sinprosp.org.br

ORLANDI, E. P. (2009) A linguagem e seu funcionamento: as formas do discurso. 5 ed. Campinas, SP: Pontes.

SACRISTÁN, J. G. Consciência e Ação sobre a prática como libertação profissional dos professores. In: NÓVOA, Antônio (Org). Profissão Professor. 2 ed. Lisboa: Porto Editora, 1995. (Coleção Ciências da Educação).

Enviado: Outubro, 2020.

Aprovado: Outubro, 2020. 